\title{
Thermal Emission analysis to predict damage in specimens of High Strength Concrete
}

\author{
Filippo Cucinotta \\ University of Messina, Italy \\ filippo.cucinotta@unime.it, http://orcid.org/0000-0002-0304-4004
}

\author{
Antonino D'Aveni \\ University of Catania, Italy \\ daveni@dica.unict.it, bttp://orcid.org/0000-0002-7178-1495
}

Eugenio Guglielmino

University of Messina, Italy

eguglie@unime.it, http:/ /orcid.org/0000-0001-7793-7406

Antonino Risitano
C.R.P.S., Italy
arisitan@gmail.com

Giacomo Risitano, Dario Santonocito

University of Messina, Italy

giacomo.risitano@unime.it, http://orcid.org/0000-0002-0506-8720

dsantonocito@unime.it,.bttp://orcid.org/0000-0002-9709-9638

ABSTRACT. In this paper thermal analysis was applied to determine the "Critical Stress" of concrete, different from its ultimate strength, able to produce the first damage in the structures under compressive loads. The Critical Stress can be thought as the stress able to produce the beginning of fatigue rupture within the material. Several specimens of high strength concrete were tested in order to define the incipient crack phenomena, also in internal part of the specimen not accessible by direct inspections, with the aid of infrared thermography. A finite element analysis completes the study and compares, for the same static loading conditions, the stress state with the experimental thermographic images. The final results show as the coupling of normal compressive test and the acquisition of the thermal images can be a useful aid to estimate a security stress value, indeed the Critical Stress, before the Ultimate Serviceability Limit (SLU) of the structure, defined as the maximum load condition before its failure.

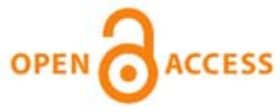

Citation: Cucinotta, F., D'Aveni, A., Guglielmino, E., Risitano, A., Risitano, G., Santonocito, D., Thermal Emission analysis to predict damage in specimens of High Strength Concrete, Frattura ed Integrità Strutturale, 55 (2021) 258-270.

Received: 19.11 .2020

Accepted: 18.12 .2020

Published: 01.01.2021

Copyright: (C) 2021 This is an open access article under the terms of the CC-BY 4.0, which permits unrestricted use, distribution, and reproduction in any medium, provided the original author and source are credited.

KEYWORDS. Crack; Critical stress; FEM; Infrared thermography. 


\section{INTRODUCTION}

S everal bridges and civil structures disasters, like Genova Morandi's viaduct, alert that the cyclical creep may have been an additional cause of the catastrophic collapse of these structures.

Fatigue phenomena on civil structures, subjected to dynamic loads over time (atmospheric phenomena, alternate loads and vibrations induced by vehicular traffic) lead to dangerous cracking, limiting the life of the structures. Indeed, during the design phase it is necessary to know not only the breaking limit of the concrete, but also the value of the "Critical Stress", lower than ultimate stress, for which irreversible cracking phenomena begins.

It is also known that the fatigue characterization of the concrete and of the pre-compressed concrete is not easy to perform due to the cost over time and to the necessary equipment for significant fatigue tests.

In the last thirty years, many studies have shown that the temperature variation of a mechanical component under stress is a good parameter for estimate the energetic release, hence the residual fatigue life of the material [1-3]. Different papers showed as the thermal analysis applied to steel specimens [4-6], to composite specimens [7-9], to welding joints [10] permit to estimate the fatigue limit of the materials in easy and rapid way.

Indeed, according to the thermo-elastic theory, under adiabatic conditions, there is a direct link between the applied stress and the temperature of the material.

In monoaxial tests, it is possible to define three phases of the temperature variation on the specimen surface in relation to the applied stress (Figure 1):

- a first phase where there is a linear correspondence between the applied load and temperature;

- a second phase where it is possible to observe the loss of linearity with a change of the slope in the temperaturestress (or deformation) curve;

- a third phase in which there is a sudden increase in temperature up to the specimen breakage.

The transition from the first to the second phase gives information about Critical Stress: this stress, if applied in a cyclical way, will lead to failure. The concrete life is affected by different factors, such as geometric ones, temperature variations, environmental and atmospheric effects and vibration phenomena. Therefore, as for aeronautical structures, it is necessary to define more accurate and programmed controls for some specific components during the design phase. The Italian technical construction code (NTC 2018) [11] defines the Ultimate Serviceability Limit (SLU) as the overload and breakage condition for a structure, even for fatigue damage. The same code defines the Serviceability Limit State (SLS) as the concrete limit stress state which produces cracks, excessive deformation and fatigue damage that may locally affect the structural integrity. No information is given about the concrete strength under cyclic loads, except for bridges.

In the present paper, the authors propose a procedure to estimate the Critical Stress of the concrete in laboratories. Although it is lower than the ultimate stress, it must be taken into consideration during the design phase.

Furthermore, finite element analyses (FEA) were performed to qualitatively compare the stress maps (numerical) with the related surface temperature maps (experimental). Finally, a careful image analysis procedure has been carried out with the Matlab® software.

\section{PHYSICAL AND THEORICAL BACKGROUND}

$\mathrm{I}$ $\mathrm{n}$ this work, the procedure used to define the Critical Stress of the concrete is based on the effect discovered by Lord Kelvin. Under adiabatic conditions, the law of variation of the solid temperature $(\Delta T)$ for mono axial mechanical stress is (Eqn. 1):

$$
\Delta \mathrm{T}=\mathrm{K}_{\mathrm{m}} \mathrm{T}_{0} \sigma_{\mathrm{m}}
$$

Where $\mathrm{K}_{\mathrm{m}}$ is the thermoelastic coefficient $\left(\mathrm{Pa}^{-1}\right), \mathrm{T}_{0}$ the specimen initial temperature $(\mathrm{K})$ and $\sigma_{\mathrm{m}}$ the average stress in the specimen cross section (MPa). The thermoelastic phenomenon has also been studied by G. Caglioti et al. in [12]. The authors defined the temperature vs. time diagram $(\Delta \mathrm{T}-\mathrm{t})$ for a steel sample during a mono axial tensile test in order to determine the yield strength $\left(\sigma_{y}\right)$ of the material. They defined the yield strength as the corresponding stress for which the temperature tangent is horizontal (point B, Figure 1). 


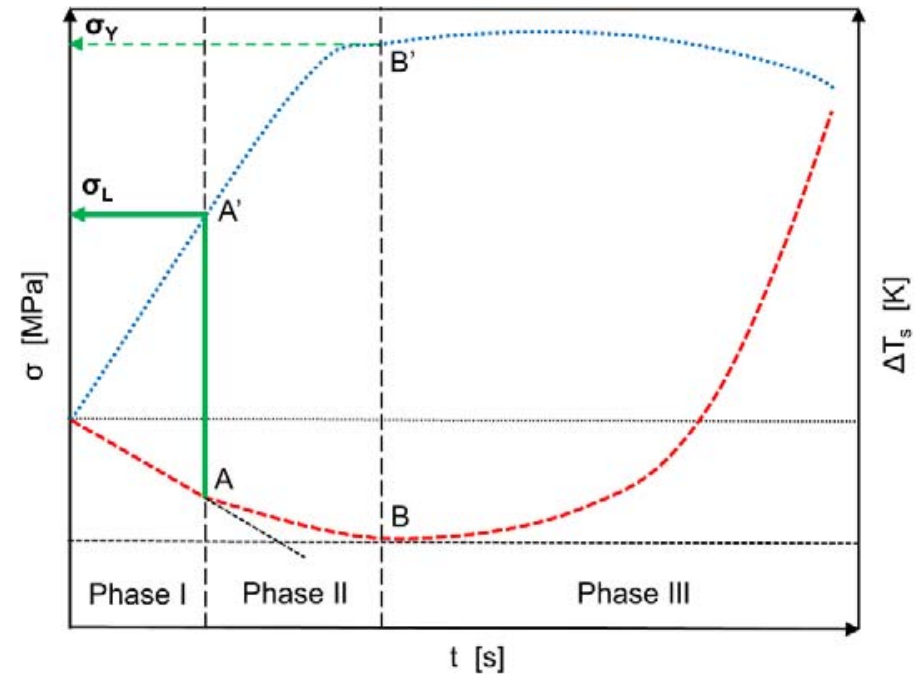

Figure 1: Qualitative $\Delta \mathrm{T}_{\mathrm{s}}$ trend vs machine time (t) vs applied stress $(\sigma)$.

Melvin et al. studied in detail the heat generated during mono axial tensile test of steel $[13,14]$. They observed that the formation of micro cracks in the steel material can be defined by the loss of linearity of the temperature vs time $(\Delta \mathrm{T}$-t.) diagram (point A, Figure 1). In fact, the temperature has a linear trend in the first part of tensile test (Phase I, elastic zone), but as the load increases it changes its trend (Phase II, mainly elastic zone; Phase III, plastic zone). They, applying the thermodynamic theory, evaluated the entropy of the phenomena as the sum of the thermodynamic forces and the fluxes (Eqn. 2):

$$
\frac{\partial \mathrm{T}}{\partial \mathrm{t}}-\mathrm{X} \nabla^{2} \mathrm{~T}=-\gamma \frac{\mathrm{T}_{0}}{\mathrm{E}}(1-2 \nu) \frac{\mathrm{d} \sigma}{\mathrm{dt}}
$$

Where $\chi$ is the thermal diffusivity $\left(\mathrm{m}^{2} / \mathrm{s}\right)$ and $\gamma$ the Gruneisen parameter. In the case of mono axial static tensile stress for a homogeneous material, Eqn. 2 becomes Eqn. 3 for a cylindrical sample with a constant stress rate (stress / time), not fast enough to neglect the viscous effects:

$$
\Delta \mathrm{T}=\mathrm{K}_{\mathrm{m}} \mathrm{T}_{0} \sigma_{\mathrm{m}}-\mathrm{B} \frac{\sigma_{\mathrm{m}}^{2}}{3 \mathrm{c}_{\mathrm{v}} \mathrm{E}}
$$

The mathematical modelling is not easy to apply in practical cases due to the uncertainty in the assessment of coefficients, particularly for $B$, linked to the Burges vector $b\left(B=M b \rho_{m} \nu^{*} / S\right)$.

In Melvin's analytical model, the loss of linearity in the temperature vs time diagram $(\Delta \mathrm{T}-\mathrm{t})$ occurs at the first micro-plasticity. This occurs before yielding as verified by numerous experimental tests.

Nowadays, the use of high precision IR sensors allows to precisely estimate the variation of the surface temperature during a monoaxial tensile test in order to define exactly the stress at which linearity is lost. Furthermore, the stress rate must be chosen very high in order to achieve adiabatic conditions. The study of the stretch of line A'-B' in Figure 1 is very important in engineering field. It is possible to link the stress at which the temperature changes during tensile (compressive) static tests to a Critical Stress on the stress vs time diagram $(\sigma-t)$. In fact, the Critical Stress coincides with the macro stress value able to produce irreversible local micro-plasticity in the material. In this case, under repeated loads, the micro plastic area increases up to produce micro cracks and fatigue failure. At the same time, it is possible to affirm that a macro stress applied during tensile (compressive) static tests produces likewise irreversible local micro-plasticity that will lead the material to fatigue failure if repetitive cycles at Critical Stress level are applied. If it is possible to identify when the linearity of thermoelastic phase is lost in the temperature vs time diagram $(\Delta \mathrm{T}-\mathrm{t}$ ) during static tensile (compressive) test, it is possible to go back to the corresponding macro stress linked to the Critical Stress. 
In the case of high strength concrete, although the homogeneity of the material is not completely realistic, the experimental tests showed some important indications about the concrete Critical Stress. In particular, during compression tests it has been possible to identify the first slope in the temperature vs time diagram $(\Delta T-t)$ and define the corresponding value of the Critical Stress.

\section{MATERIAL AND METHODS}

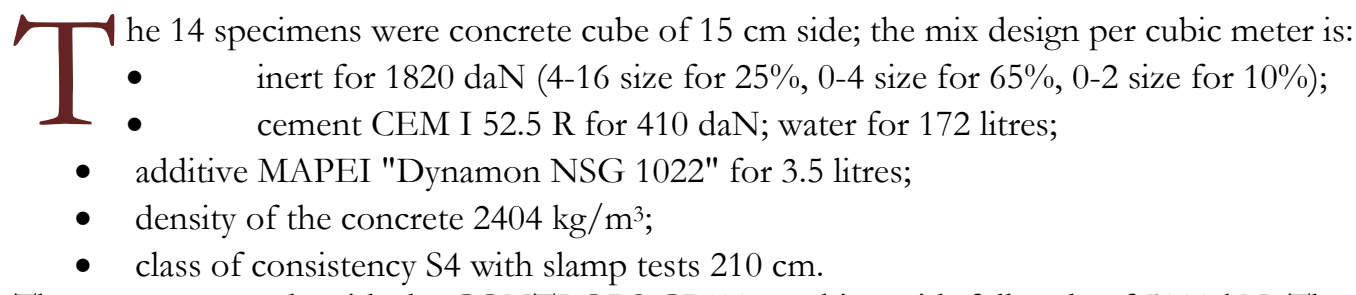

The tests were made with the CONTROLS C7600 machine with full scale of $5000 \mathrm{kN}$. The applied uniaxial compression stress rate was $1 \mathrm{MPa} / \mathrm{s}$. The tests were carried out in load control at constant speed (N/s). The thermal images were acquired by FLIR SC300 IR camera.

Figure 2 shows a concrete specimen loaded at left side (a) and thermal image of the same specimen surface at the beginning of the test at right side (b). In Figure $2 \mathrm{~b}$ the analysed zones (square) and the reference temperature of the tests (image zero) are indicated.

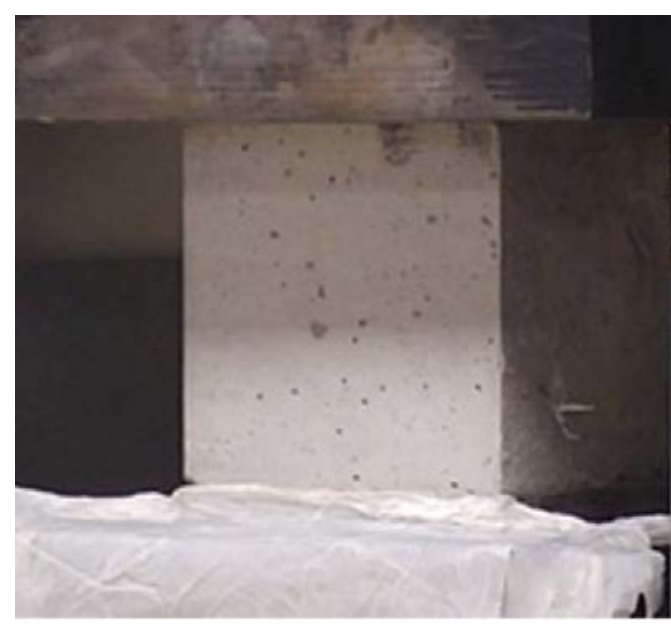

(a)

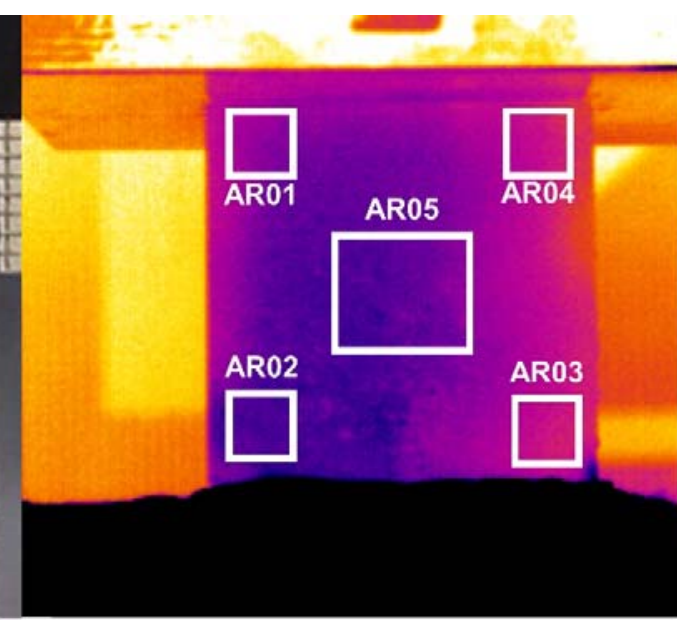

$26,0^{\circ} \mathrm{C}$

(b)

Figure 2: a) adopted specimen; b) thermal image of one face at the beginning of the test with the analysed areas (square).

The maximum value of temperature within the five detection areas (AR01 to AR05) was recorded during the execution of the tests with an acquisition frequency of $10 \mathrm{~Hz}$.

In order to correlate the thermal images with the stress map of the specimen, a static finite element analysis was conducted using Ansys ${ }^{\circledR}$ APDL. A cubic concrete specimen (Figure 3a) with the same geometry of the ones adopted for experimental tests was modelled. As in the experimental tests, the specimen was bonded with two rigid plates and the uniaxial load was applied on it through the rigid top plate. The concrete specimen was modelled with hexa SOLID186 element type and the material characteristics of high strength concrete $(E=30 \mathrm{GPa}, v=0,2)$ with linear elastic behaviour were used. The contact zones between the plates of the test machine and the specimen were modelled as a surface-to-surface contact using CONTA174 elements for the specimen surfaces and TARGE170 for the rigid plates. In the FE analysis a "rough" contact model was taken into account since, as observed by Dai and Lam [15] on compressive tests of short concrete-filled elliptical steel columns, a large friction model between the plates and the surface of the specimen seems to adequately predict the contact behaviour in tangential direction.

The rigid top plate was loaded at its pilot node and was fixed in all its d.o.f. except in the vertical displacement direction, while the bottom rigid plate was totally fixed (all the six d.o.f. are blocked) through its pilot node. 
A convergence analysis (Figure 3b) on the vertical displacement of the central node of the specimen was conducted with different lengths of the finite elements, ranging from $5 \mathrm{~mm}$ to $25 \mathrm{~mm}$. In order to obtain a better resolution of the stress field on the external specimen surface, 31.114 finite elements of $5 \mathrm{~mm}$ size were chosen for an appropriate comparison with the thermal images.

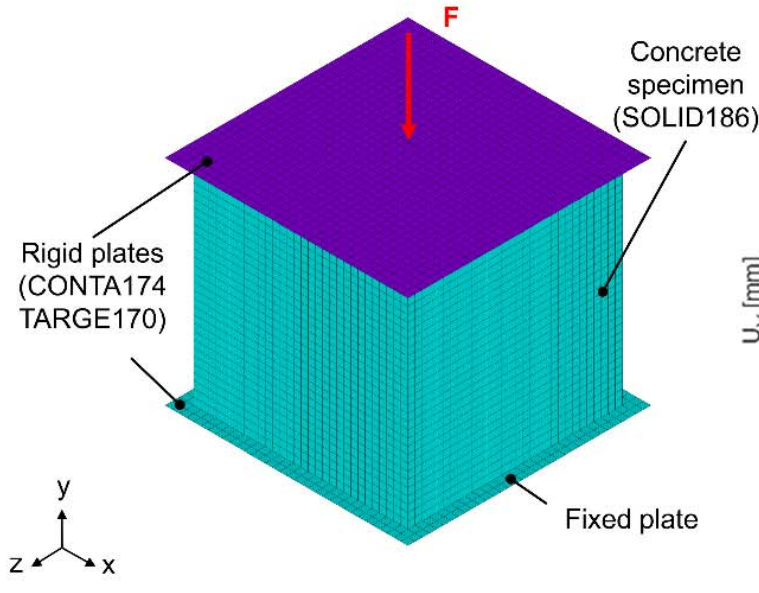

(a)

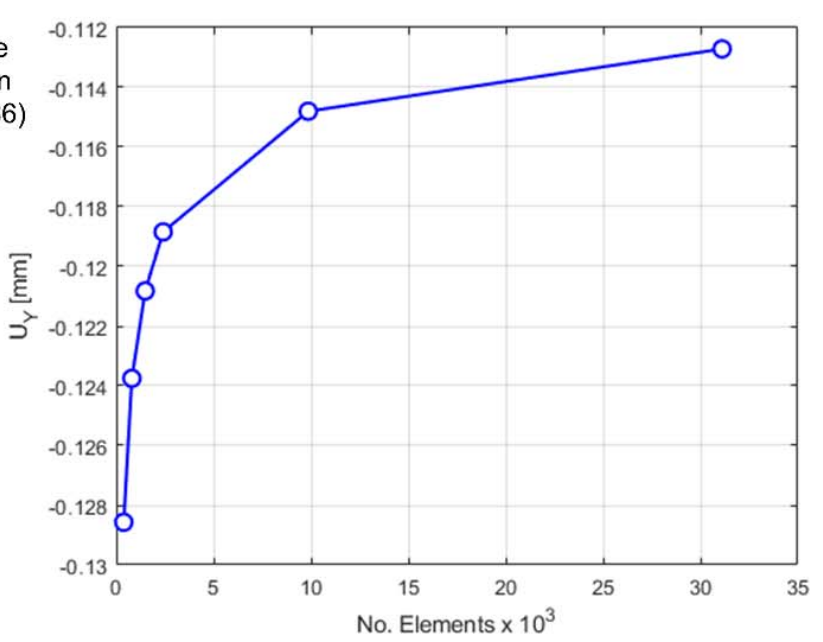

(b)

Figure 3: a) Finite element model of the cubic concrete specimen and b) convergence analysis on the vertical displacement of the specimen central node.

For a better presentation of the results, the image analysis of the acquired thermal maps has been carried out, adopting a procedure developed in Matlab $\AA$, as follows:

- Subtraction of the ambient temperature in order to emphasize the difference in temperature of the sample surface. The ambient temperature was detected as the average temperature inside a rectangular area outside the sample but with the same reflectivity.

- Noise reduction by Gaussian filter with standard deviation $\mathrm{SD}=8$. The Gaussian filter replaces the value of each pixel with the weighted average value of the contiguous pixels. In this way the thermal map is smoother and less influenced by noise and anisotropies.

- Displaying by means of isotherm contours. The contours highlight better the different thermal areas and help to better understand the behaviour of the specimen.

In Figure 4, an example of image analysis of the specimen surface temperature has been reported for a determined load condition.

It is evident how the image processing allows to clearly improve the ability to distinguish the colder areas from the warmer ones. Furthermore, the 3D surface mapping help to clearly render the heat distribution on the external surface of the specimen, as in Figure 5.

The 3D surface of the equivalent stress on the external surface of the sample, as predicted by the FEA, is reported in Figure 6. It shows the expected hourglass shape due to compressive loads.

\section{RESULTS AND ANALYSIS}

thermal analysis on concrete specimens during classic compressive static test was performed. The temperature vs.
time vs. stress diagrams shown:
s. A linear trend typical of the thermoelastic phase. At this stage, there are no microcracks and, therefore, the
second term of Eqn. 3 is not relevant.

2. A second phase in which the points are well interpolated by means of a second straight line with a different slope. The intersection of the two lines defines the Critical Stress; where micro-faults begin to appear in the internal structure of the concrete sample. In fact, the heat is released by plastic deformations. In the analytical model, the contribution of the 
second term of Eqn. 3 increases more and more due to the effect of the applied compressive mean stress $\left(\sigma_{\mathrm{m}}\right)$ with a clearly visible temperature variation that continues until the specimen fails. Figs. 7-10 show the temperature recorded in characteristic points of the specimen surface during the loading phase.

(a) Absolute temperature

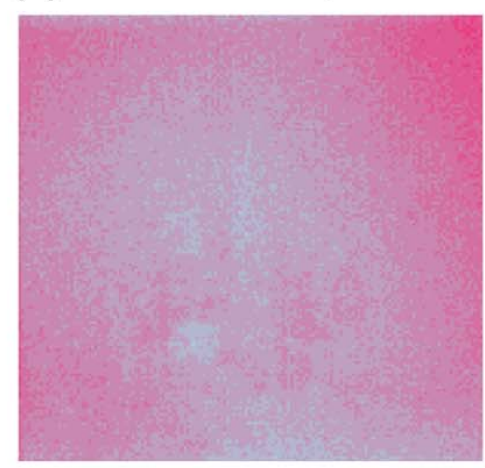

(c) Gaussian filter

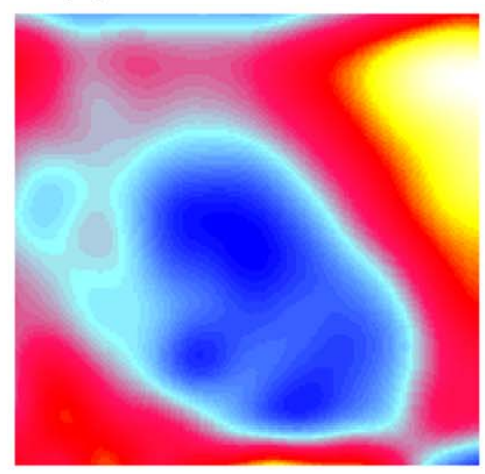

(b) Relative temperature

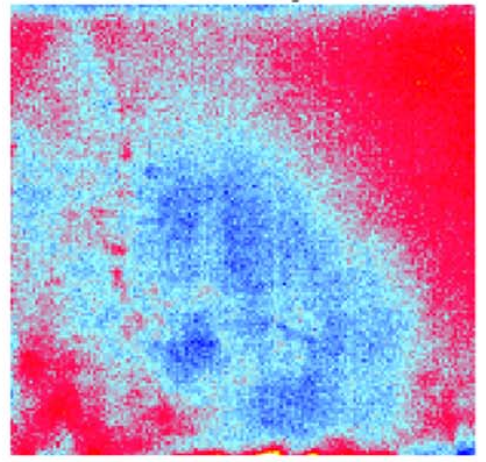

(d) Isotherm contours [K]

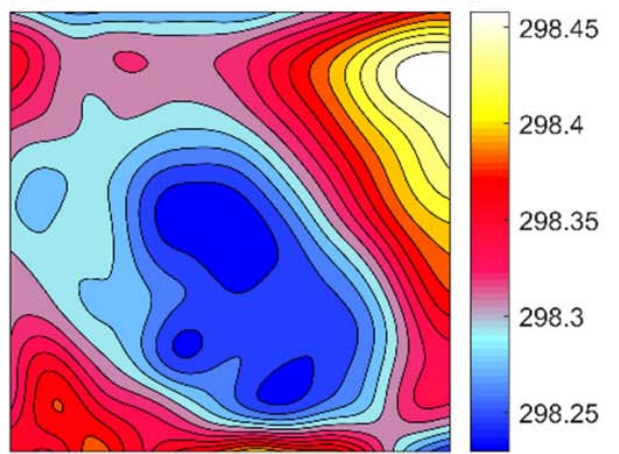

Figure 4: Thermal image processing steps: a) absolute temperature detected by IR camera; b) the ambient temperature is subtracted; c) noise reduction by means of a Gaussian filter $(\mathrm{SD}=8)$; $\mathrm{d})$ the isotherm contours are plotted.

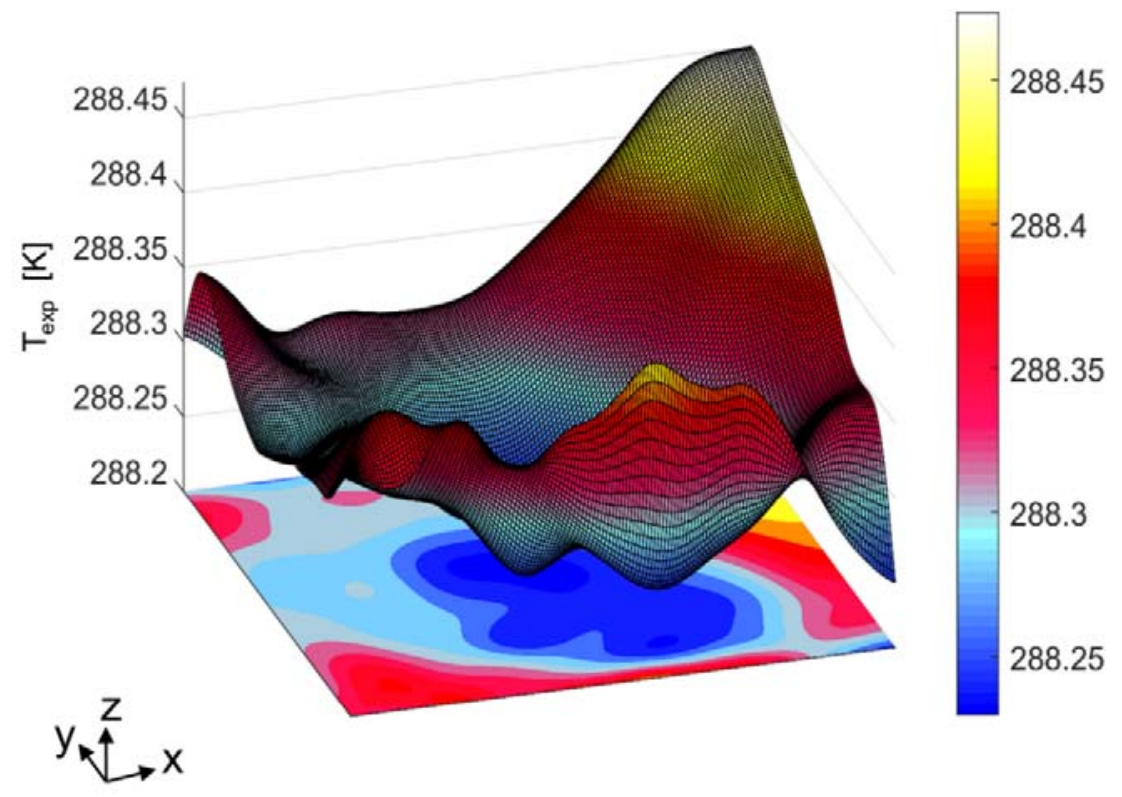

Figure 5: 3D rendering of the experimental thermal map on the specimen surface. 


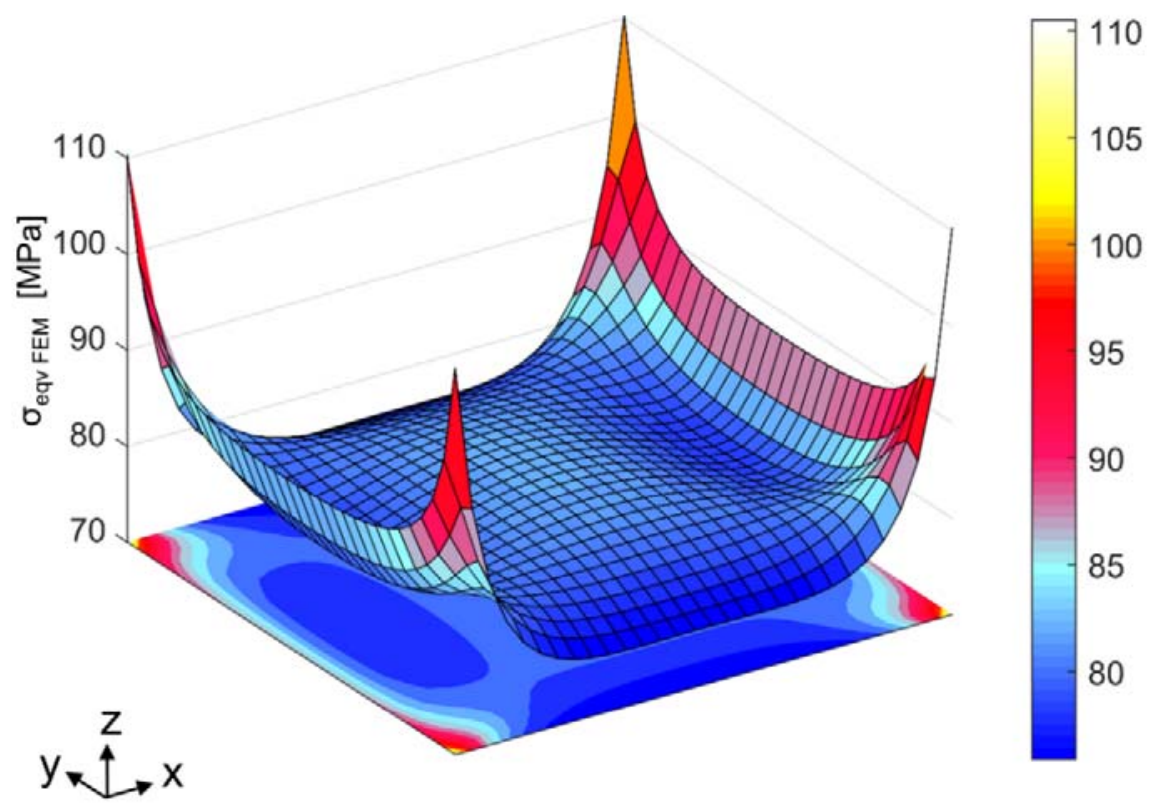

Figure 6: 3D rendering of the Equivalent stresses estimated by FEM on the specimen surface.

In Figure 7, related to second tested specimen, the temperature data for the centre (AR05, area no. 5 of Figure 2) of specimen surface is reported. The intersection of the two straight lines (in black) define the Critical Stress for the concrete $\sigma_{\mathrm{cL}}$ at 44.2 MPa.

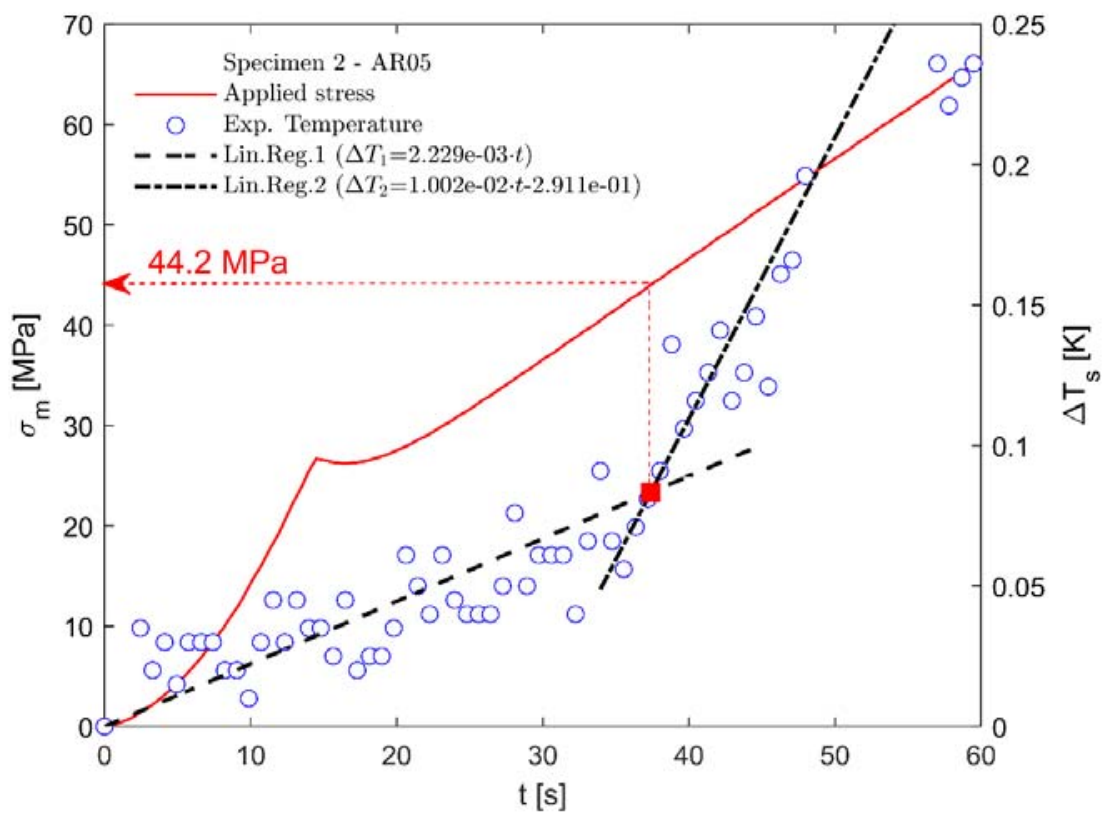

Figure 7: $\Delta \mathrm{T}$ vs time curve (blue points) and stress vs time curve (red line) for area AR05 of Specimen 2.

In Figure 8, the data for the area located in the upper right corner (AR04, area no. 4 of the specimen of Figure 2) are reported. The corner area AR04 shows a different trend compared to the central area AR05 for the same concrete specimen; in fact, the temperature drops continuously. For area AR04, the change in slope is much less noticeable than in area AR05. 
These behaviours are perfectly congruent with the stresses in the two examined areas: compressive stress for the central area AR05 and tensile stress for the upper right corner area AR04. The next two figures (Figure 9 and Figure 10) are related to a different area of the test performed on specimen no. 11. Also in this case, the previously seen phenomena are shown again.

It can be summarized that in all tests, a temperature trend similar to the one already described was observed. In particular, the temperate trend of area AR05 was used to determine the Critical Stress on the stress-time diagram.

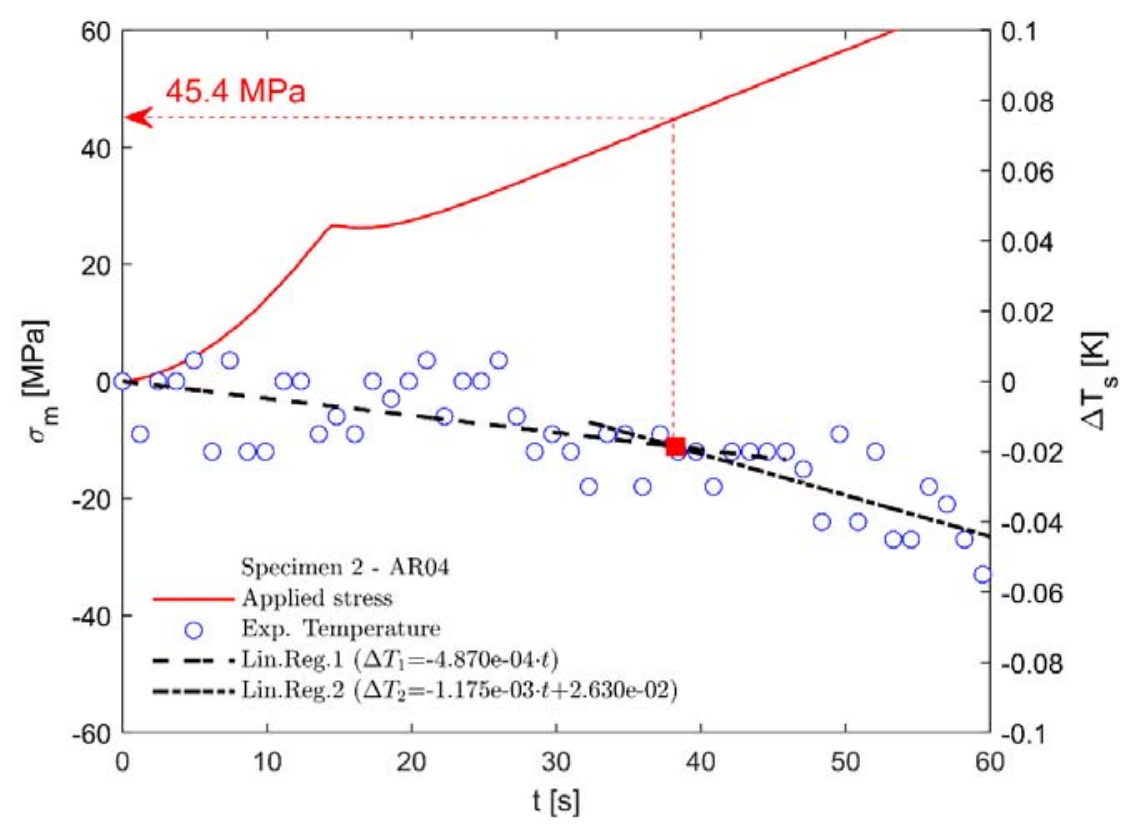

Figure 8: $\Delta \mathrm{T}$ vs time curve (blue points) and stress vs time curve (red line) for area AR04 of Specimen 2.

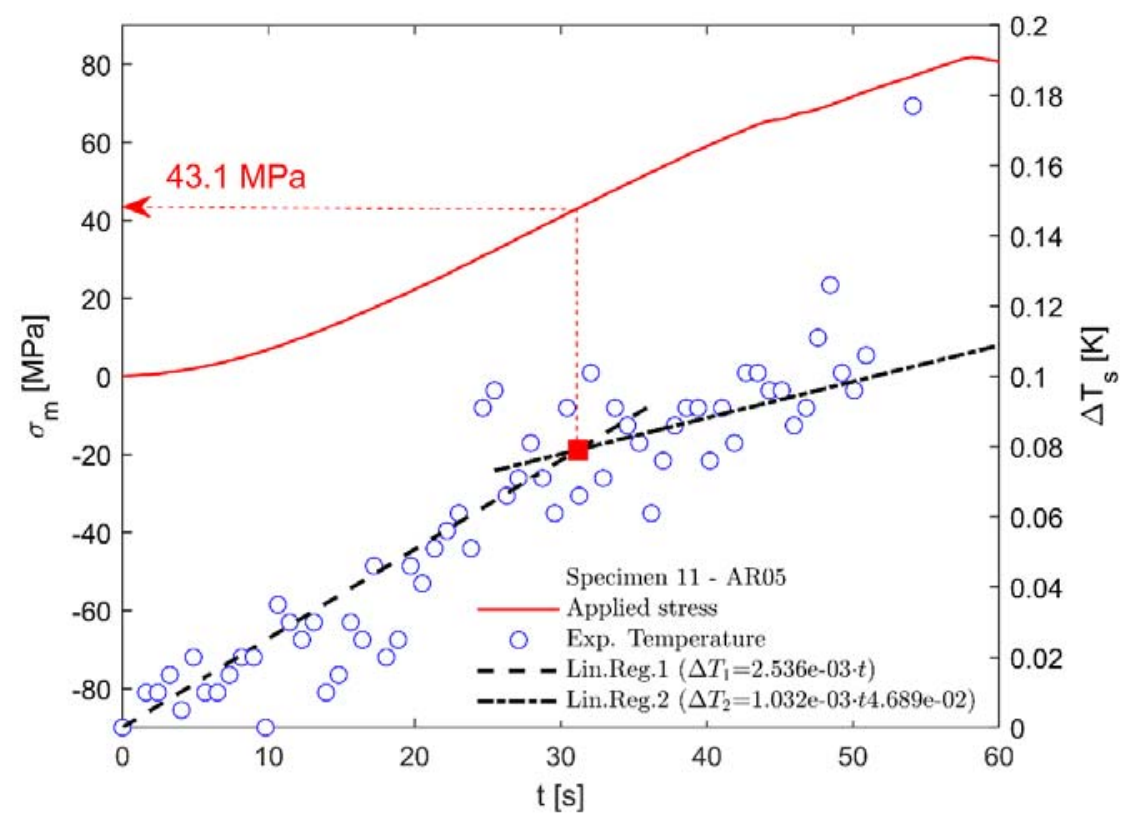

Figure 9: $\Delta \mathrm{T}$ vs time curve (blue points) and stress vs time curve (red line) for area AR05 of Specimen 11. 


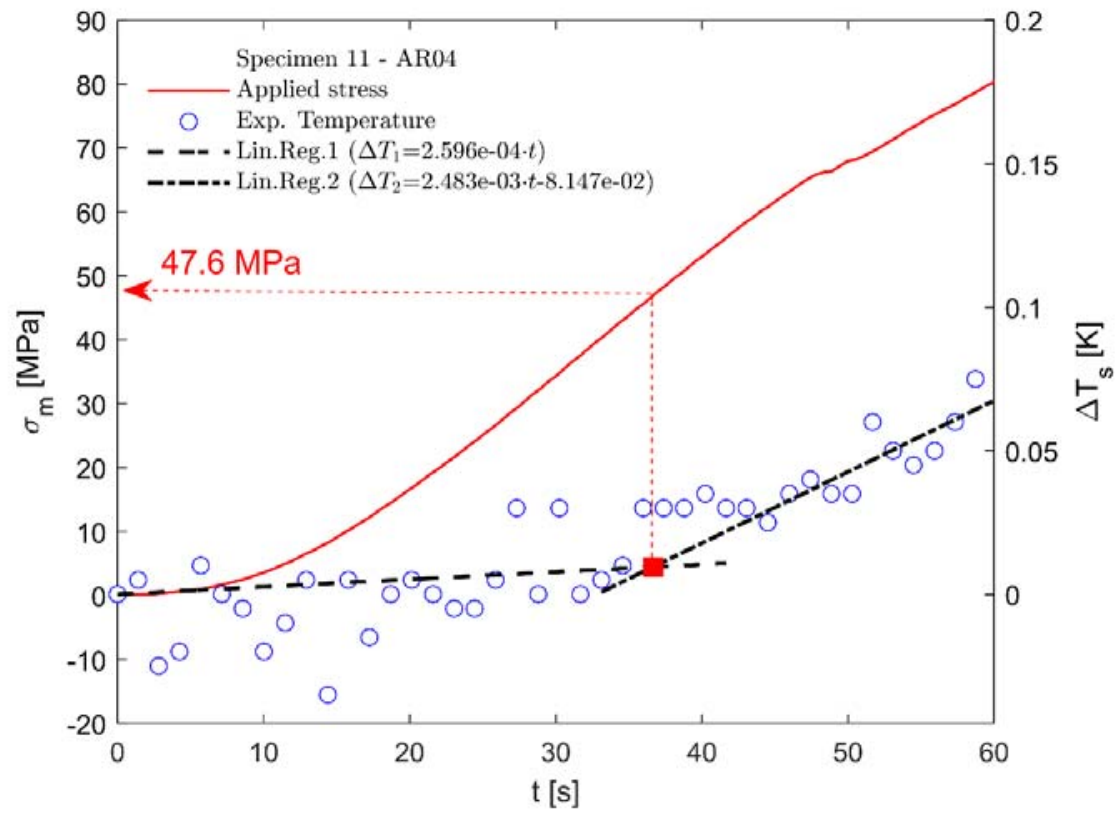

Figure 10: $\Delta \mathrm{T}$ vs time curve (blue points) and stress vs time curve (red line) for area AR04 of Specimen 11.

Figure 11 shows a comparison of the picture taken after the breakage (a), the original IR image (b) and the processed IR image (c) recorded immediately before the breakage of the specimen no. 14. It is possible to observe the distribution of temperatures, linked to the stresses. In the centre of the specimen it is completely different from the four corner areas (AR01-04). This is due to the plate of the testing machine that activate a distorted stress state. The value of the critical load at the corner, related to the intersections point of two temperature interpolating straight lines, is about $1000 \mathrm{kN}$, despite the plate effect on the corner areas. This value is practically comparable with the one recorded on the central area AR05.

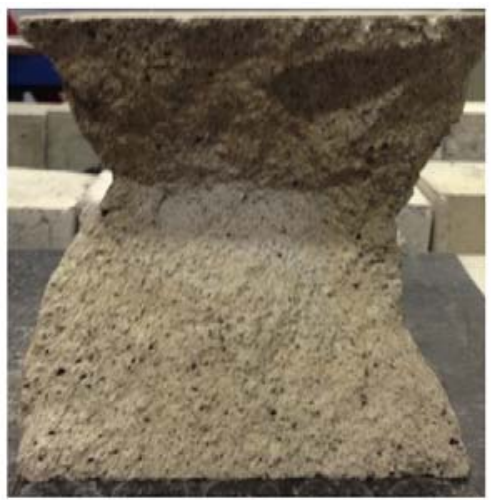

(a)

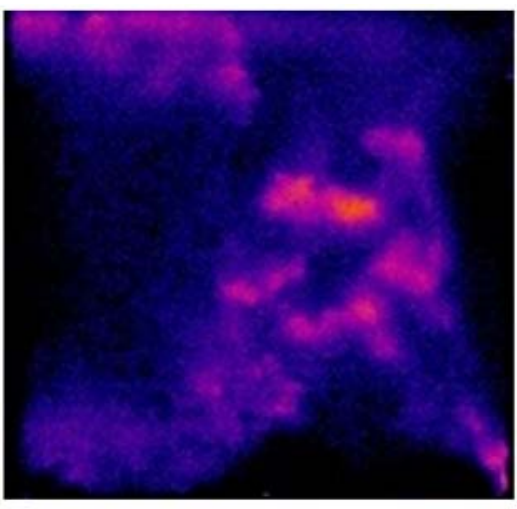

(b)

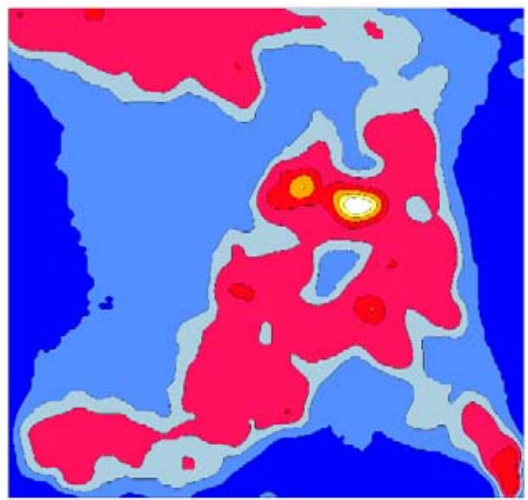

(c)

Figure 11: a) picture after the breakage of the specimen; b) original IR image and c) processed IR image before of the breakage.

In summary, the thermoelastic effect (first phase) of concrete is perfectly visible and the cubic Critical Stress can be determined from the $\Delta \mathrm{T}$ vs time curves $\left(\sigma_{\mathrm{cL}} \approx 36 \mathrm{MPa}\right)$. This cubic Critical Stress is slightly less than the Italian code compressive stress limit $\left(\sigma_{\mathrm{c}, \max }=0.60 \mathrm{x} \mathrm{R}_{\mathrm{ck}}=43,57 \mathrm{MPa}\right.$, with $\mathrm{R}_{\mathrm{c}}$ cubic compressive strength of concrete at 28 days $)$ at the limit state serviceability (SLS) for the load characteristic combination (Italian code NTC 2018 - paragraph 4.1.2.2.5.1). This small difference in values suggests to investigate the effects of cyclical loads (wind effect for instance) also on the durability of civil structures. 


\begin{tabular}{|c|c|c|c|c|c|}
\hline \multirow{2}{*}{ Specimen no. } & \multirow{2}{*}{$\begin{array}{l}\text { Strength } \\
\mathrm{R}_{\mathrm{c}}[\mathrm{MPa}]\end{array}$} & \multicolumn{2}{|c|}{$\begin{array}{l}\text { Concrete Critical } \\
\text { Stress } \sigma_{\mathrm{cL}}[\mathrm{MPa}]\end{array}$} & \multicolumn{2}{|c|}{$\mathrm{r}=\sigma_{\mathrm{cL}} / \mathrm{R}_{\mathrm{c}}$} \\
\hline & & $\begin{array}{l}\text { at the } \\
\text { Center }\end{array}$ & $\begin{array}{l}\text { at the } \\
\text { Corner }\end{array}$ & $\begin{array}{l}\text { at the } \\
\text { Center }\end{array}$ & $\begin{array}{l}\text { at the } \\
\text { Corner }\end{array}$ \\
\hline 1 & 82 & 45 & 43 & 0.55 & 0.52 \\
\hline 2 & 77 & 54 & 46 & 0.70 & 0.60 \\
\hline 3 & 88 & 68 & 58 & 0.77 & 0.66 \\
\hline 4 & 79 & 51 & 46 & 0.64 & 0.58 \\
\hline 5 & 84 & 47 & 53 & 0.55 & 0.63 \\
\hline 6 & 79 & 47 & 44 & 0.59 & 0.56 \\
\hline 7 & 84 & 43 & 44 & 0.51 & 0.53 \\
\hline 8 & 73 & 52 & 53 & 0.72 & 0.73 \\
\hline 9 & 101 & 60 & 38 & 0.60 & 0.38 \\
\hline 10 & 80 & 51 & 53 & 0.64 & 0.67 \\
\hline 11 & 89 & 49 & 36 & 0.55 & 0.40 \\
\hline 12 & 84 & 47 & 42 & 0.55 & 0.50 \\
\hline 13 & 82 & 31 & 40 & 0.38 & 0.49 \\
\hline 14 & 82 & 53 & 42 & 0.65 & 0.51 \\
\hline Average $\left(\mathrm{R}_{\mathrm{cm}}\right)$ & 83.3 & 49.8 & 45.7 & 0.60 & 0.554 \\
\hline Standard Deviation (SD) & 6.51 & 8.42 & 6.56 & 0.0982 & 0.0996 \\
\hline
\end{tabular}

Characteristic value

$72.62 \quad 35.99 \quad 34.94$

$\mathrm{R}_{\mathrm{ck}}=\left(\mathrm{R}_{\mathrm{cm}}-1,64 \mathrm{xSD}\right)$

Table 1: cubic strength $\mathrm{R}_{\mathrm{c}}$ and Critical Stress $\sigma_{\mathrm{cL}}$ of the concrete.

In order to correlate the thermal images with the internal stress of the cubic concrete specimen, a finite element analysis was conducted with a load equal to the previously found critical load of about $1000 \mathrm{kN}$. The equivalent Von Mises stresses on the external surface of the cubic specimen, calculated by the FE analysis (on right) and compared with the thermal map (on left), are reported in

Figure 12. The values of the stress agree with the ones found experimentally and reported in Table 1 (about 50 MPa, central area), therefore the finite element model is well calibrated.

In both the images reported in

Figure 12 it is possible to highlight: the corner area (1) in which there are both the maximum of temperature and stress; the central area (2) in which there are the relative minimum values of the temperature and the relative maximum of the equivalent stress; the lateral area (3) in which there are the relative maximum of temperature and the relative minimum of stress; the contact area with the plates (4) in which there is the negative peak of temperature, due to the heat dissipation caused by the steel plates and the local contact stresses.

Basically, the two colormaps have a roughly mirrored behaviour. This is because, where there is an increase of the stresses due to an expansion of the material, there is a consequent lowering of the temperature. This behaviour is more evident on a median horizontal section, in which the curve temperature and the correspondent equivalent stress curve appear almost reflected (Figure 13). 


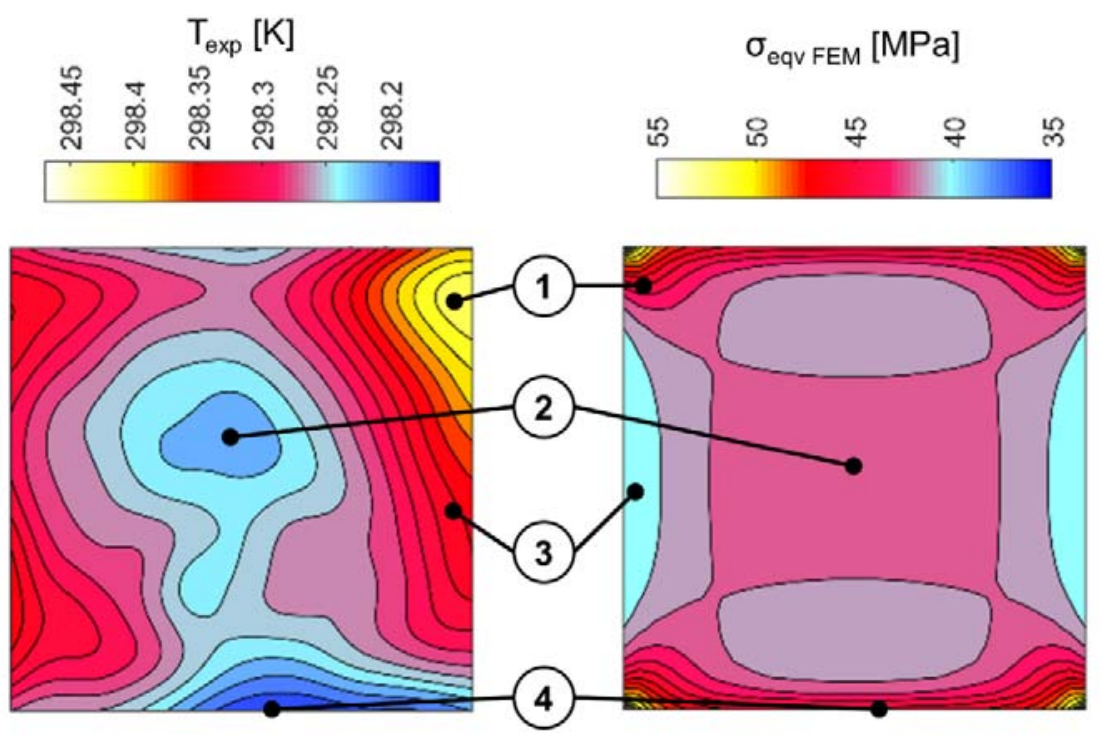

(a)

(b)

Figure 12: a) Thermal map and b) FEM Equivalent von Mises Stress for the critical load (1000 kN).

The examination of the thermal images of all the specimens shows the possibility to identify the lines and the areas in which the concrete material shall begin to fail locally. In Figure 14, the stress distributions of four different load levels (500, 1000, 1500 and $1900 \mathrm{kN}$ ) calculated by FEM are compared with the experimental IR images of a specimen at the same load levels. The colormaps of temperature and the equivalent stress at the four different load conditions are reported using the same colormap. The load equal to $1900 \mathrm{kN}$ corresponds to the beginning of failure. In all the maps it is possible to observe the expected hourglass shape, due to the freedom of expansion of the lateral specimen surfaces and to the constraints of the plates of the machine.

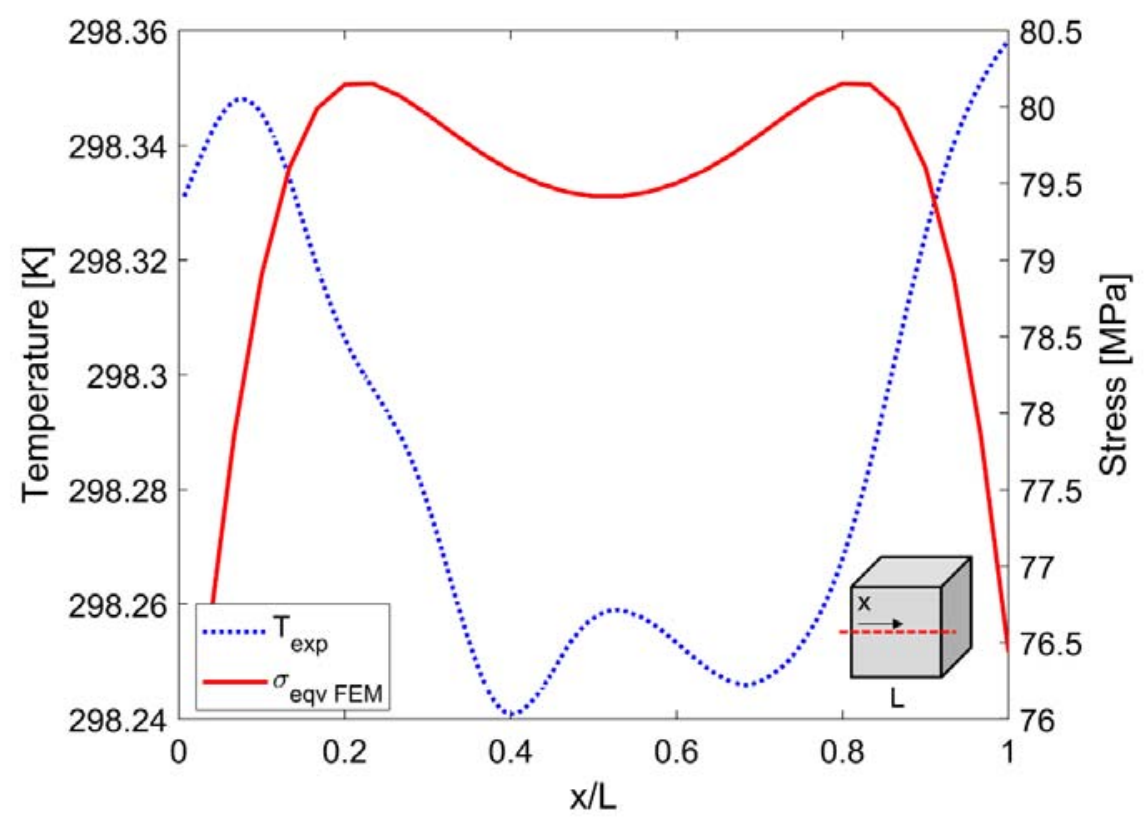

Figure 13: Experimental temperature and FEM equivalent von Mises stress curves on a median horizontal section of the specimen. 


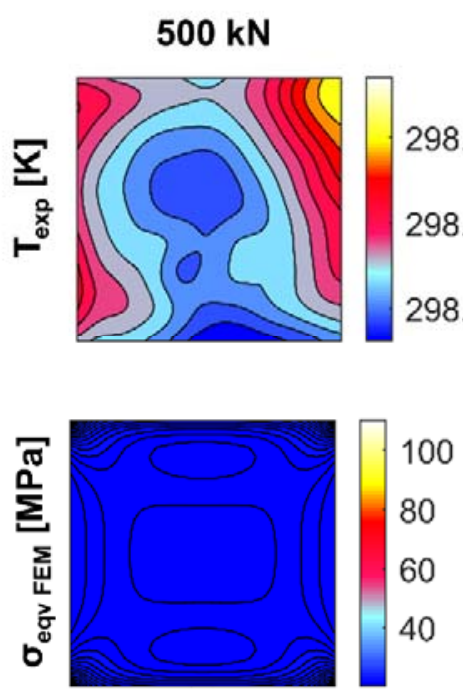

(a)
$1000 \mathrm{kN}$

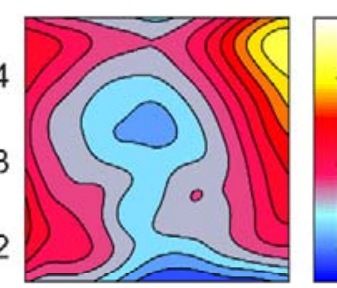

$1500 \mathrm{kN}$

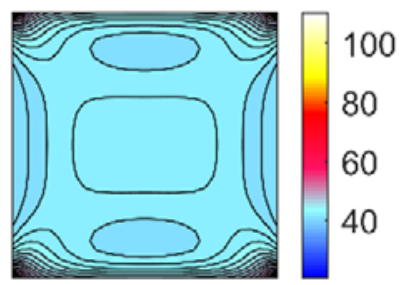

(b)
298.4

298.3

298.2

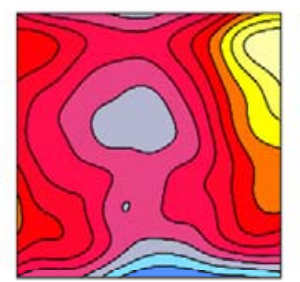

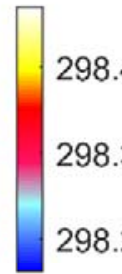

$1900 \mathrm{kN}$

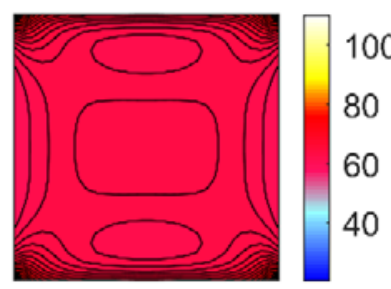

(c)

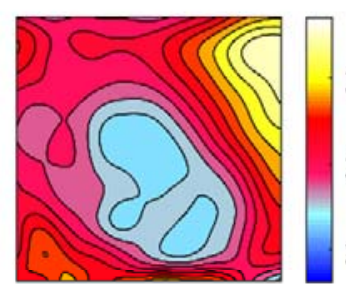

298.4

298.3

298.2

Figure 14: Comparison between a) experimental thermal and b) equivalent stress distribution on the specimen.

For loads much lower than the ultimate load of the material (500 and $1000 \mathrm{kN}$ ), it is difficult to identify the possible failure area, while the temperature line become more marked close to the ultimate load. The temperature gives indications about the possible beginning of cracking within the concrete specimen as is well shown for 1500 and $1900 \mathrm{kN}$ loads. In particular, for loads close to the concrete ultimate load it is easy to identify the path along which the specimen should break. The stress maps reported in

Figure 12 and Figure 14 show the hourglass shape, as it was observed in the concrete specimens after the breakage (Figure 11a).

\section{CONCLUSIONS}

$\mathrm{I}$ n order to identify the Critical Stress value $\sigma_{\mathrm{cL}}$, coinciding with the first local plasticization (not visible to human eye), a test campaign was performed on 14 samples of high strength concrete under classic uniaxial static compression tests using the thermographic technique.

The examination of the heat maps developed for four different load levels and of the related stress maps obtained through FEM confirms the validity of the proposed procedure. According to an experimental protocol, already adopted for other materials by Risitano et Al. [4,5], the Critical Stress $\sigma_{\mathrm{cL}}$ (load/area of the cross section) can be defined.

The results of the research shown how the thermal analysis permits to identify the stress that produces the first local cracking in the specimen, with loads different and lower $(50 \%-70 \%)$ from the breaking load $\mathrm{R}_{\mathrm{ck}}$. In addition, the loss of linearity in the temperature-stress (strain) diagram, permits to associate the Critical Stress of concrete to the stress value that defines the beginning of fatigue phenomena.

On the basis of the results, it is possible to state also:

1. The Italian code NTC 2018 (paragraph 4.1.2.2.5.1) for concrete, which identifies for the Serviceability State Limit (SLS) the limit compressive stress $\sigma_{\mathrm{c}} \leq(0.45$ to 0.60$) \mathrm{f}_{\mathrm{ck}}$, seems to be adequate.

2. The procedure adopted permits, by means of static uniaxial compression test, to define in a more accurate way the allowable stress in the legal field ( 0.45 to $\left.0.60 \mathrm{f}_{\mathrm{ck}}\right)$.

3. A suitable protocol test may be adopted, both in the testing stage and in the working stage, as non-destructive method to determine the Critical Stress of the concrete specimen or structure components.

4. The proposed method can be very useful in the pre-project phase in which the designer, with easy compression tests, can know the value of the allowable compressive stresses for the load combination at serviceability state limit (SLS). 


\section{ACKNOWLEDGEMENTS}

hanks for the supply of concrete specimens to I.C.E.A. companies Ltd - Industry and premixed concrete - S.P. n. 3 km 0:30 - Zona Industriale Piano Tavola 95032 Belpasso (CT)

\section{REFERENCES}

[1] Risitano, A., Risitano, G. (2010). Cumulative damage evaluation of steel using infrared thermography. Theor Appl Fract Mech 54, pp. 82-90. DOI: 10.1016/j.tafmec.2010.10.002.

[2] Clienti, C., Fargione, G., La Rosa, G., Risitano, A., Risitano, G. (2010). A first approach to the analysis of fatigue parameters by thermal variations in static tests on plastics. Eng Fract Mech 77, pp. 2158-2167. DOI: $10.1016 /$ j.engfracmech.2010.04.028.

[3] Risitano, A., Risitano, G. (2013). Cumulative damage evaluation in multiple cycle fatigue tests taking into account energy parameters. Int J Fatigue 48, pp. 214-222. DOI: 10.1016/j.ijfatigue.2012.10.020.

[4] Risitano, A., Risitano, G. (2013). Determining fatigue limits with thermal analysis of static traction tests. Fatigue Fract Eng Mater Struct 36, pp. 631-639. DOI: 10.1111/ffe.12030.

[5] Ricotta, M., Meneghetti, G., Atzori, B., Risitano, G., Risitano, A. (2019). Comparison of Experimental Thermal Methods for the Fatigue Limit Evaluation of a Stainless Steel. Metals (Basel) 9, pp. 677. DOI: 10.3390/met9060677.

[6] Corigliano, P., Cucinotta, F., Guglielmino, E., Risitano, G., Santonocito, D. (2020). Fatigue assessment of a marine structural steel and comparison with Thermographic Method and Static Thermographic Method. Fatigue Fract Eng Mater Struct 43, pp. 734-743. DOI: 10.1111/ffe.13158.

[7] Colombo, C., Vergani, L., Burman., M. (2012). Static and fatigue characterisation of new basalt fibre reinforced composites. Compos Struct 94, 1165-1174. DOI: 10.1016/j.compstruct.2011.10.007.

[8] Palumbo, D., De Finis, R., Demelio, P.G., Galietti, U. (2017). Early detection of damage mechanisms in composites during fatigue tests. Conf. Proc. Soc. Exp. Mech. Ser., 8, p. 133-141. DOI: 10.1007/978-3-319-42195-7_19.

[9] Crupi, V., Guglielmino, E., Risitano, G., Tavilla, F. (2015). Experimental analyses of SFRP material under static and fatigue loading by means of thermographic and DIC techniques. Compos Part B Eng 77, pp. $268-277$. DOI: 10.1016/j.compositesb.2015.03.052.

[10] Corigliano, P., Epasto, G., Guglielmino, E., Risitano, G. (2017). Fatigue analysis of marine welded joints by means of DIC and IR images during static and fatigue tests. Eng Fract Mech 183, pp. 26-38. DOI: $10.1016 /$ j.engfracmech.2017.06.012.

[11] Norme Tecniche per le Costruzioni (NTC 2018). Italy: Gazzetta Ufficiale n.42 del 20/02/2018, Supplemento ordinario n.8; 2018.

[12] Caglioti, G., Ferro, Milone, A. (1982). Società italiana di fisica. Mechanical and thermal behaviour of metallic materials: Varenna on Lake Como, Villa Monastero, North-Holland Pub. Co.

[13] Melvin, A.D., Lucia, A.C., Solomos, G.P., Volta, G., Emmony, D. (1990). Thermal emission measurements from creep damaged specimens of AISI 316L and Alloy 800H. Proc 9th Int Conf Exp Mech 2, pp. 765-773.

[14] Melvin, A.D., Lucia, A.C., Solomos, G.P. (1993). The thermal response to deformation to fracture of a carbon/epoxy composite laminate. Compos Sci Technol 46, pp. 345-51. DOI: 10.1016/0266-3538(93)90180-O.

[15] Dai, X., Lam, D. (2010). Numerical modelling of the axial compressive behaviour of short concrete-filled elliptical steel columns. J Constr Steel Res 66, pp. 931-42. DOI: 10.1016/j.jcsr.2010.02.003. 